\title{
Erratum to: Three-Parallel Reed-Solomon Decoder Using S-DCME for High-Speed Communications
}

\author{
Jae Do Lee $\cdot$ Myung Hoon Sunwoo
}

Published online: 28 February 2012

(C) Springer Science+Business Media, LLC 2012

Erratum to: J Sign Process Syst (2012) 66:15-24

DOI 10.1007/s11265-010-0517-2

The original version of this article unfortunately contained a mistake on the acknowledgements. The one of the acknowledgement was misstated and should be corrected. A sentence about the IT R\&D program of MKE/KEIT has to be revised to NRF and international cooperation program.

A corrigendum is summarized as below.

"This work was supported by Mid-career Researcher Program through the National Research Foundation (NRF) grant of Korea funded by the MEST (20110016671), by the framework of international cooperation program managed by NRF of Korea (2011-0030930) and by IC Design Education Center (IDEC)."

The online version of the original article can be found at http//dx. doi.org/10.1007/s11265-010-0517-2.

J. D. Lee $\cdot$ M. H. Sunwoo $(\bowtie)$

School of Electronics and Computer Engineering, Ajou University,

San 5, Wonchun-Dong, Yeungtong-Gu,

443-779 Suwon, Korea

e-mail: sunwoo@ajou.ac.kr 